\title{
Effects of amnioinfusion in meconium-stained amniotic fluid complicating pregnancy
}

\author{
J. Princy Emil Josephine ${ }^{1 *}$, M. Shanthi ${ }^{2}$
}

\begin{abstract}
${ }^{1}$ Department of Obstetrics and Gynaecology, Kanyakumari Medical College, Kanyakumari, Tamil Nadu, India ${ }^{2}$ Rathna Memorial Hospital, Kanyakumari, Tamil Nadu, India
\end{abstract}

Received: 06 July 2021

Revised: 04 August 2021

Accepted: 08 August 2021

\section{*Correspondence:}

Dr. J. Princy Emil Josephine,

E-mail: ogprincy80@gmail.com

Copyright: () the author(s), publisher and licensee Medip Academy. This is an open-access article distributed under the terms of the Creative Commons Attribution Non-Commercial License, which permits unrestricted non-commercial use, distribution, and reproduction in any medium, provided the original work is properly cited.

\section{ABSTRACT}

Background: In our country a major cause of perinatal mortality and morbidity is MAS (MAS) in new-born. The aim of the study was to assess feto-maternal outcome following intrapartum amnioinfusion in patients with meconiumstained amniotic fluid and Neonatal intensive care unit (NICU) admission following intrapartum amnioinfusion in patients with meconium stained amniotic fluid.

Methods: This prospective observational study was conducted on 200 patients with pregnancy at or beyond 37 weeks in active labour with moderate to thick meconium stained liqour following spontaneous rupture or Artificial rupture of membranes (ARM). In 100 patients amnioin fusion was performed and rest 100 were in control group. Continuous electronic fetal heart rate (FHR) monitoring was performed. Emergency lower segment caesarean section (LSCS) was done when fetal bradycardia was recorded or in case of non-progress of labor. Fetomaternal outcome will be noted.

Results: In present study there were more cases of fetal distress in the control group (38) compared with the amnioinfusion group (24). 34 patients in the amnioinfusion group and 38 patients in the control group were delivered by LSCS. The incidence of MAS in amnioinfusion group was 3 in number where as 14 in number of control group. Similarly, in our study 13 neonates of amnioinfusion group and 31 neonates of control group were needed admission in NICU.

Conclusions: Intrapartum amnioinfusion in meconium-stained amniotic fluid by diluting the meconium and by decreasing the cord compression decreases the incidence of foetal distress and there by decreases incidence of MAS in neonates and NICU admission, these all leads to decrease the incidence of maternal and perinatal morbidity and mortality.

Keywords: Amnioinfusion, Meconium-stained amniotic fluid, NICU

\section{INTRODUCTION}

Amniotic fluid serves several functions, such as providing a medium for fetal growth and development, protecting the fetus from external trauma and maintaining intrauterine temperature. Meconiumstained amniotic fluid occurs in $12 \%$ of all pregnancies: in $5 \%$ of these (1: 200 of all pregnancies) the meconium is aspirated in to the lungs of the fetus. ${ }^{1}$ MAS contributes to neonatal death in approximately $10 \%$ of babies who aspirate (1: 2000 of all pregnancies). In the past, it was considered as a sign of fetal distress occurring only in response to hypoxia. But in most cases meconium in the amniotic fluid is benign and associated with term pregnancies. But there is a general agreement that the presence of meconium-stained amniotic fluid is associated with increase in perinatal mortality and morbidity. Many investigators do not believe that presence of meconium predict a poor outcome unless it is accompanied by other signs of fetal distress. However, if aspirated by the fetus before or during delivery, meconium can obstruct the airways, interfere 
with gas transfer and cause respiratory difficulties. The increased perinatal mortality and morbidity in the presence of meconium-stained amniotic fluid is mainly due to Meconium aspiration syndrome (MAS) occurring in $2-10 \%$ of these neonates. $50-60 \%$ of infants whose amniotic fluid was meconium stained was reported to have meconium in their tracheas. ${ }^{2}$ Treatment strategies of deep suctioning of hypopharynx and nares during delivery and immediate tracheal suctioning after birth have been successful in reducing MAS. But despite aggressive airway cleaning, meconium aspiration is not always prevented, the causative factor being in-utero aspiration.

Amnioinfusion is a simple technique, which dilutes the amniotic fluid and has been studied as an additional tool to prevent meconium aspiration. It helps by physical dilution of the thick meconium and hence decreases the toxic effects of aspiration of thick meconium. It also increases the fluid around the fetus and thereby decreases cord compression and hence fetal hypoxia when present.

The objective of this study was to evaluate the effect of amnioinfusion in meconium-stained amniotic fluid on the incidence of intrapartum fetal heart rate abnormalities, the nature of labour and incidence of instrumental deliveries, the neonatal outcome, the incidence of MAS in neonates.

\section{METHODS}

The study was conducted at Kanyakumari medical college hospital, Kanyakumari during the period of September 2019 to August 2020. For this prospective randomized controlled clinical study, 200 women in labor at term with moderate or thick Meconium-stained amniotic fluid were included. Term pregnancies, with gestational age between 37 and 41 weeks, singleton pregnancies, vertex presentation with normal fetal heart rate and rhythm, intact membranes at the admittance of the study and having moderate or thick meconiumstained amniotic fluid on spontaneous rupture of membranes or after doing artificial rupture of membranes in labor ward were included in the study.

While multiple pregnancies, fetal malpresentations, fetal congenital anomalies pre-labour rupture of membranes polyhydramnios, antepartum hemorrhage, medical disease complicating pregnancies- anemia, heart disease, diabetes mellitus, pregnancy induced hypertension, thin meconium-stained liquor, were excluded from the study each patient was carefully examined for the presence of any risk factors. Gestational age was confirmed by detailed menstrual history, clinical examination and previous scan report if present. The amniotic fluid was examined after spontaneous rupture of membranes on artificial rupture of membranes and graded thin, moderate and thick meconium. These patients were categorized into amnioinfusion group and no amnioinfusion group randomly as 1:1 ratio. The first patient was given amnioinfusion whereas second patient was taken as control group (without amnioinfusion). The procedure was explained to the patient and consent obtained.

The amnioinfusion was given as $1000 \mathrm{ml}$ of normal saline over $40 \mathrm{~min}$. The control group did not receive any catheter placement. Both groups were managed in the labour ward routinely. In the amnioinfusion group the NST tracing was repeated after giving amnioinfusion. In control group the NST tracing was repeated after 1 hour. Progress of the labour was monitored and obstetric assistance was given whenever necessary. Forceps application and delivery by caesarean section were done for fetal heart rate abnormalities or failure to progress such as arrest disorders or protraction disorder as indicated. After delivery patients were observed in labour ward for two hours and then shifted to postnatal ward.

Babies were followed prospectively till the day of discharge from the hospital. SPSS version 21 was used for statistical analysis. Percentile analysis was used for distribution of all characteristics. Chi square tests were used to analyse the significance of categorical variables. $P$ value less than 0.05 was considered significant.

\section{RESULTS}

In our study group of 200 patients, 100 were in amnioinfusion group and 100 were in control group, in both groups most common age group was $21-25$ years. In this study the age of the amnioinfusion group is matching with the control group, there was no significant difference between groups. Coming to parity too it was similar distribution, most of mothers were mostly nullipara or had one child before. In this study socio economic status of amnioinfusion group matching with the control group. In both groups socio-economic status (SES) 4 and 5 were predominant, in which is among 100 in amnioinfusion group 42 belong to SES 4 and rest 58 in SES 5, while in control group 40 belonged to SES 4 and 60 in SES 5, no patients were in other socioeconomic status.

In this study both groups were matching in relation to their gestational age. Most of the patients were between 37 to 39 weeks. In amnioinfusion group 85 patients were in the active phase of labour compared to 83 in the control group. In control group 17 patients were in the latent phase of labour compared to 15 patients in amnioinfusion group. Both the groups were matching with the phase of labour in inclusion.

Oxytocin augmentation was required in 64 patients in amnioinfusion group and 67 patients in control group. Both the groups were matching with the oxytocin augmentation requirement. There were more cases of fetal distress in the control group (38) compared with 
the amnioinfusion group (24) (Table 1). P value was $<0.05$. This shows that amnioinfusion causes a significant reduction in fetal heart rate abnormality during labor. This was statistically significant too. Similarly, on evaluation of type FHR abnormalities in both group amnioinfusion significantly reduces the incidence of variable deceleration, it was present in 4 cases in control group in compared to 4 cases in amnioinfusion group. In control group there is no change in both NST tracings.

Table 1: Intra-partam FHR abnormalities.

\begin{tabular}{|lll|}
\hline $\begin{array}{l}\text { Fetal heart } \\
\text { abnormalities }\end{array}$ & $\begin{array}{l}\text { Amnioinfusion } \\
\text { group }\end{array}$ & $\begin{array}{l}\text { Control } \\
\text { group }\end{array}$ \\
\hline Present & 24 & 38 \\
\hline Absent & 76 & 62 \\
\hline
\end{tabular}

When mode of delivery is considered 61 in amnioinfusion group and 51 in control group delivered by labour natural (Table 2). 2 patients in amnioinfusion group and six patients in control group had outlet forceps delivery. Low mid cavity forceps used in 3 patients belonging to the amnioinfusion group and 4 patients in the control group. Vacuum forceps was needed in 1 patient in control group and none in the amnioinfusion group. 34 patients in the amnioinfusion group and 38 patients in the control group were delivered by LSCS. This shows that amnioinfusion is not influencing the mode of delivery.

Table 2: Mode of delivery.

\begin{tabular}{|lll|}
\hline Mode of delivery & $\begin{array}{l}\text { Amnioinfusion } \\
\text { group }\end{array}$ & $\begin{array}{l}\text { Control } \\
\text { group }\end{array}$ \\
\hline LN & 61 & 51 \\
\hline Outlet & 2 & 6 \\
\hline LMC & 3 & 4 \\
\hline Vacuum & 0 & 1 \\
\hline
\end{tabular}

This study 39 patients of amnioinfusion group and 49 patients of control group were needed instrumental delivery. Whereas 61 patients in amnioinfusion group and 51 patients were delivered by labour natural. Fetal distress was the indication for instrumental delivery in 24 patients of amnioinfusion group and 38 patients in control group. Whereas other causes were the indication for instrumental delivery in 15 patients of amnioinfusion group and 10 patients in control group and one patient in control group delivered by vacuum. Amnioinfusion decreases the incidence of fetal distress. This was statistically significant also.

One-minute Apgar less than 4 was seen in 3 infants in amnioinfusion group and 10 infants in control group, 57 was seen in 76 infants in amnioinfusion group and 89 infants in control group. 8-10 Apgar score was seen in 21 infants in amnioinfusion group and one infant in control group. Similarly, five-minute Apgar score more than 7 was seen in 91 infants in amnioinfusion group and 49 infants in control group. Both one minute and five-minute Apgar score were significantly higher in amnioinfusion group.

In this study, grading of the meconuim in inclusion of the amnioinfusion group matching with the control group, in amnioinfusion group 75 had moderate meconium stained liqour and rest 25 had thick meconium while in control group it was 78 vs 22 . In this study the presence of meconuim below the vocal cord was significantly raised in control group.

The incidence of MAS in amnioinfusion group 3 in number (presence of meconium below the vocal cord were in 10 patients) whereas 14 in number of control group (presence of meconium below the vocal cord were in 27 patients). This was significant statistically with p value less than 0.05 (Table 3 ).

Table 3: Incidence of meconium aspiration syndrome.

\begin{tabular}{|lll|}
\hline MAS & $\begin{array}{l}\text { Amnioinfusion } \\
\text { group }\end{array}$ & $\begin{array}{l}\text { Control } \\
\text { group }\end{array}$ \\
\hline Present & 3 & 14 \\
\hline Absent & 97 & 86 \\
\hline
\end{tabular}

Similarly, in our study 13 neonates of amnioinfusion group and 31 neonates of control group were needed admission in NICU. Amnioinfusion reduces the need of admission in NICU significantly. Among which 7 neonates in the amnioinfusion group and 13 neonates in the control group were admitted for observation. 3 neonates of the amnioinfusion group and 4 of the control group were admitted for birth asphyxia, whereas 14 neonates of the control group and 3 of the amnioinfusion group were admitted for MAS. MAS is the predominant cause for the NICU admission in the control group.

Finally, to the important outcome perinatal morbidity and mortality were increase in the control group. Amnioinfusion decrease the perinatal morbidity and mortality, this was also statistically significant (Table 4).

Table 4: Perinatal morbidity and mortality.

\begin{tabular}{|lll|}
\hline Perinatal outcomes & $\begin{array}{l}\text { Amnioinfusion } \\
\text { group }\end{array}$ & $\begin{array}{l}\text { Control } \\
\text { group }\end{array}$ \\
\hline Perinatal morbidity & 13 & 31 \\
\hline Perinatal mortality & $0 / 100$ & $2 / 100$ \\
\hline
\end{tabular}

\section{DISCUSSION}

In this prospective study, patients with moderate and thick meconium-stained amniotic fluid, 100 patients received amnioinfusion and 100 patients did not receive 
amnioinfusion. The amnioinfusion group and control group were matched with respective to age, parity and gestational age.

More patients in both the groups were in the active phase of labour on inclusion than latent phase but this difference was not significant. The number of patients receiving oxytocin for augmentation is not influenced by amnioinfusion $(64 \%$ vs $67 \%$, p value $>0.05)$.

But in the study by Vsta et al the amnioinfusion group had significantly higher incidence of oxytocin use than the control group (44\% vs $23 \%$, p value $<0.001) .{ }^{3}$ The study of Cialone et al also showed the patient receiving amnioinfusion had greater oxytocin requirement in labour. ${ }^{4}$

In this study there was no significant difference between the two groups in the rupture of membrane to delivery interval ( $2.44 \mathrm{hrs}$ vs $2.24 \mathrm{hrs}$ ). This was correlating with the study of Cialone et al in which the rupture of membrane to delivery interval was similar in both groups. ${ }^{4}$ Vsta et al showed longer interval in the amnioinfusion group. ${ }^{3}$

The incidence of fetal distress in this study was $24 \%$ in the amnioinfusion group and $38 \%$ in the control group $(p<0.05)$. This was statistically significant. This is in par with Wenstrom and Parson study which showed decrease in the incidence of fetal distress in the amnioinfused patients. ${ }^{5}$ But in contrast study by Rogers et al showed a higher incidence of fetal distress in the amnioinfused group. $(30.5 \%$ vs $19.7 \%) .{ }^{6}$ It also demonstrated that the incidence of fetal distress was not significantly different between the two groups, which is in contrast to this study.

Taking into account on the phase of labour on inclusion most of the patients in latent phase of labour delivered by caesarean section while most of the patients in the active phase of labour on inclusion delivered vaginally.

There was no significant difference between the two groups regarding the mode of delivery. In this study the number of operative deliveries for fetal distress were significantly lower than that in control group (24\% vs $38 \%$, p value $<0.05)$. This is similar to the result in the study by Rathore et al (12\% vs $26 \%$ ). Hoodley et al also reported similar findings. ${ }^{6-8}$ Ericsen et al and Sponge et al reported no effect on caesarean section for fetal distress. $^{9,10}$ Vsta et al reported a higher incidence of caesarean delivery in the amnioinfusion group (28\% vs $17 \%)$ especially for fetal distress $(16 \%$ vs $11 \%){ }^{3}$ The CRAMP 1 and 2 also showed no significant difference in the caesarean section rates for fetal distress between the two groups. ${ }^{11}$

In this study, the one-minute Apgar score $<4$ was 3\% vs $10 \%$ (p value $<0.05$ ). One-minute Apgar score 5-7 was $76 \%$ vs $89 \%$ (p value<0.05) and one-minute Apgar score $8-10$ was $21 \%$ vs $1 \%$ (p value<0.05). 5-minutes Apgar score $<7$ was $9 \%$ vs $48 \%$, p value $<0.05$. 8-10 was $91 \%$ vs $49 \%$, p value $<0.05$. Hence the fetal outcome was good with the amnioinfusion group than the control group. Rathore et al reported similar findings in their study. The studies by Wenstrom et al, Marci et al, Keith et al showed a significant decrease number of babies with low Apgar in the amnioinfusion group. 5,7,12,13

In this study, the presence of meconium below the level of vocal cord was significantly reduced in the amnioinfusion group ( $10 \%$ vs $27 \%$, p value $<0.05)$. The incidence in the other studies given. All the studies show a reduction in the incidence of meconium below the level of vocal cord with amnioinfusion except that of Sponge et al and Vsta et al. , $^{3,10}$

The incidence of MAS in this study 3 in amnioinfusion group vs 14 in control group ( $p$ value $<0.05$ ). This shows that there is significant decrease in the incidence of MAS and related sepsis in the amnioinfusion group. All the studies we have quoted here show decrease in the incidence of MAS with amnioinfusion.

In this study 13 neonates from the amnioinfusion group and 31 from the control group needed admission in the NICU. This shows that there was a significant decrease in the neonatal admissions in the amnioinfusion group (13\% vs $31 \%$, p value<0.05). CRAMP 2 Zimbabwe arm showed similar results $(12.8 \%$ vs $22.9 \%) .{ }^{14}$ The study by Rathore et al also showed decreased neonatal admissions in the amnioinfusion group (3\% vs $11 \%){ }^{7}$ Studies by Cialone et al and CRAMP 1 South African arm also showed similar results. ${ }^{4,11}$

In this study, the perinatal mortality rate in the amnioinfusion group is $0 \%$ while in the control group is $2 \%$. The difference was not significant statistically. In the CRAMP 2 study conducted in Zimbabwe the perinatal mortality was $1.2 \%$ in amnioinfusion group vs $3.6 \%$ in the control group. In the study by Rathore et al the perinatal moratality rate was $2 \%$ in the amnioinfusion group and $5 \%$ in the control group. ${ }^{7}$ Mukhopadhyaye et al showed a perinatal mortality rate of $2 \%$ in the amnioinfusion group and $11 \%$ in the control group. ${ }^{15}$

\section{CONCLUSION}

In this study it is found that the use of amnioinfusion has significantly reduced the number of intrapartum fetal heart rate abnormalities. The incidence of caesarean deliveries is not reduced but the number of caesarean section done for fetal distress has been decreased by the use of amnioinfusion.

The study shows a drastic improvement in the perinatal outcome in the patients who received amnioinfusion. There was significant improvement in the one minute and five-minutes Apgar score, decrease in the incidence 
of meconium below the level of vocal cord and decrease in MAS. The number of babies admitted in NICU due to sepsis and MAS is also significantly reduced in the amnioinfusion group.

To conclude, amnioinfusion is a safe, easy and effective procedure, which needs little expertise and can be done in labour ward even with limited facilities to improve neonatal outcome in meconium stained liqour. The use of such simple technique is very useful and effective in developing countries even with limited newborn care facilities. It is also very cost effective.

\section{Limitations}

This study was done in small sample size, cases taken in a shorter duration, further study in large scale was warranted to assess the perfect outcome of maternal and fetal morbidity also taking other related complications into account.

Funding: No funding sources

Conflict of interest: None declared

Ethical approval: The study was approved by the Institutional Ethics Committee

\section{REFERENCES}

1. Oyelese Y, Culin A, Ananth CV, Kaminsky LM, Vintzileos A, Smulian JC. Meconium-stained amniotic fluid across gestation and neonatal acid-base status. Obstet Gynecol. 2006;108(2):345-9.

2. Addisu D, Asres A, Gedefaw G, Asmer S. Prevalence of meconium stained amniotic fluid and its associated factors among women who gave birth at term in Felege Hiwot comprehensive specialized referral hospital, North West Ethiopia: a facility based crosssectional study. BMC Pregnancy Childbirth. 2018;18(1):429.

3. Usta IM, Mercer BM, Aswad NK, Sibai BM. The impact of a policy of amnioinfusion for meconiumstained amniotic fluid. Obstet Gynecol. 1995;85(2):237-41.

4. Cialone PR, Sherer DM, Ryan RM, Sinkin RA, Abramowicz JS. Amnioinfusion during labor complicated by particulate meconium-stained amniotic fluid decreases neonatal morbidity. Am J Obstet Gynecol. 1994;170(3):842-9.

5. Wenstrom KD, Parsons MT. The prevention of meconium aspiration in labor using amnioinfusion. Obstet Gynecol. 1989;73(4):647-51.

6. Lo KW, Rogers M. A controlled trial of amnioinfusion: the prevention of meconium aspiration in labour. Aust N Z J Obstet Gynaecol. 1993;33(1):51-4.

7. Rathor AM, Singh R, Ramji S, Tripathi R. Randomised trial of amnioinfusion during labour with meconium stained amniotic fluid. BJOG. 2002;109(1):17-20.

8. Moodley J, Matchaba P, Payne AJ. Intrapartum amnioinfusion for meconium-stained liquor in developing countries. Trop Doct. 1998;28(1):31-4.

9. Eriksen NL, Hostetter M, Parisi VM. Prophylactic amnioinfusion in pregnancies complicated by thick meconium. Am J Obstet Gynecol. 1994;171(4):102630.

10. Spong CY, Ogundipe OA, Ross MG. Prophylactic amnioinfusion for meconium-stained amniotic fluid. Am J Obstet Gynecol. 1994;171(4):931-5.

11. Mahomed K, Mulambo T, Woelk G, Hofmeyr GJ, Gulmezoglu AM. The Collaborative Randomised Amnioinfusion for Meconium Project (CRAMP): 2. Zimbabwe. Br J Obstet Gynaecol. 1998;105(3):30913.

12. Macri CJ, Schrimmer DB, Leung A, Greenspoon JS, Paul RH. Prophylactic amnioinfusion improves outcome of pregnancy complicated by thick meconium and oligohydramnios. Am $\mathbf{J}$ Obstet Gynecol. 1992;167(1):117-21.

13. Keith WK, Rogers M. A controlled trial of amnioinfusion: the prevention of meconium aspiration in labour. Aust NZ Obstet Gynecol, 1993; 33(1):51-4.

14. Hofmeyr GJ, Xu H. Amnioinfusion for meconiumstained liquor in labour. Cochrane Database Syst Rev. 2010;(1):14.

15. Mukhopadhyay G, Burman SK, Sikder K, Chatterjee B. Intrapartum amnioinfusion in meconium stained amniotic fluid and fetal outcome. AICOG. 2003.

Cite this article as: Josephine JPE, Shanthi M. Effects of amnioinfusion in meconium-stained amniotic fluid complicating pregnancy. Int J Reprod Contracept Obstet Gynecol 2021;10:3504-8. 